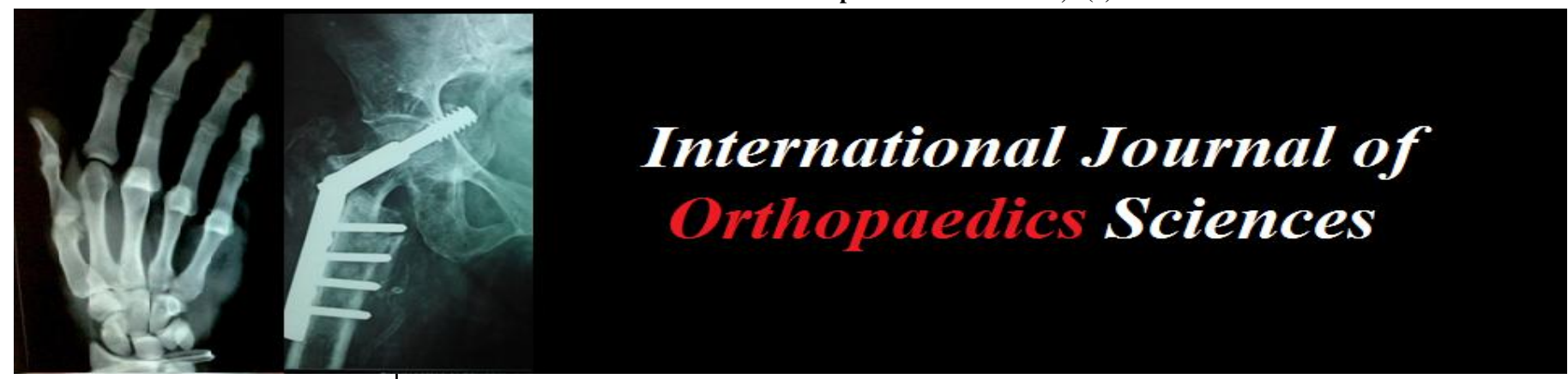

E-ISSN: 2395-1958

P-ISSN: 2706-6630

IJOS 2020; 6(4): 612-618

(C) 2020 IJOS

www.orthopaper.com

Received: 02-08-2020

Accepted: 28-08-2020

Sirazul Haque Malik

SRHU, Jollygrant Dehradun,

Uttarakhand, India

Chetan Peshin

SRHU, Jollygrant Dehradun,

Uttarakhand, India

Anil Kumar Juyal

SRHU, Jollygrant Dehradun,

Uttarakhand, India

Tejasvi Agarwal

SRHU, Jollygrant Dehradun,

Uttarakhand, India
Corresponding Author:

Chetan Peshin

SRHU, Jollygrant Dehradun,

Uttarakhand, India

\section{Intra-medullary interlocking nail in extra-articular distal third tibia fractures}

\author{
Sirazul Haque Malik, Chetan Peshin, Anil Kumar Juyal and Tejasvi \\ Agarwal
}

DOI: https://doi.org/10.22271/ortho.2020.v6.i4i.2394

\section{Abstract}

Background: This study was performed to evaluate the results of intramedullary nailing of extraarticular distal tibial fractures.

Methods: 24 tibial fractures that involved the distal 3rd of the tibia which were treated with reamed intramedullary nailing using either two or three distal interlocking screws. Obtained Radiographs were examined to determine the immediate and final alignments and fracture healing.

Results: The average time to union was 15.6 weeks.

Conclusions: Intramedullary nailing is found to be an effective alternative for the treatment of distal metaphysealtibial fractures.

Keywords: Third tibia, interlocking nail, metaphysealtibial fractures

\section{Introduction}

Fractures of the distal third of tibial shaft occurs commonly as a consequence of road traffic accident, fall from height, sports and direct injury ${ }^{[1]}$.

Various modalities of treatment have been reported till date with advantages and disadvantages of each modality. Conservative management, closed reduction and interlocking nailing, open reduction and plating, minimally invasive percutaneous plate osteosyntheis and external fixation are some of the modalities presently available for the treatment of these fractures.

Distal tibial fractures are quite challenging in terms of treatment even for mostof the experienced surgeons. Tibia is a subcutaneous bone with vulnerable soft tissue coverage resulting local soft tissue problems and delayed bone healing. Soft tissue breakdown and bone healing are major complications and the risk is more with open reduction and internal fixation [2].

Fractures of the distal third tibia are different, in that the bone is subcutaneous with no muscle covering on the anteromedial aspect and consequently less blood supply to the tibia. This precarious vascularity, as compared to other long bones, may lead to delayed union or nonunion. Treatment remains a major substantial therapeutic challenge in orthopedic trauma; considering its anatomy, it is difficult to achieve reduction and maintain it owing to wide metaphysis, bad skin condition, and fracture comminution ${ }^{[3]}$. In addition, it is even more difficult if fibula fractures are at the same level, which contribute to additional mechanical instability and associated syndesmotic injury if fibula fractures occur in the lower $10 \mathrm{~cm}$ area.

Various modalities are available, such as

- Interlock Nailing

- External fixation spanning ankle joint

- Minimally invasive plate osteosynthesis (MIPO) with locking plates

Intramedullary Nailing is indicated for the majority ofclosed lower third tibia and middle and lower thirdjunction fractures of the tibia ${ }^{[4]}$ as well as for open fractureswith adequate soft tissue cover when fracture is notextending into the lower $4 \mathrm{~cm}$ of tibia from the anklejoint ${ }^{[5]}$. 
Minimally Invasive Plate Osteosynthesis (MIPPO) with Locking Plates

Displaced, unstable fractures of distal third of tibia,mainly fractures within $3 \mathrm{~cm}$ from ankle joint - with orwithout articular involvement ${ }^{6}$ - provide best indicationsfor plating, particularly when skin envelop is good andpatient can afford; Patients which were treated with MIPPO are notincluded in the present study.

\section{Advantages of Closed Nailing over Plating}

- In closed nailing, fracture hematoma is preserved,which is vital and essential for fracture healing; which yields high union rate.

- If it is done intramedullary it acts as a loadsharingimplant. So, early weight bearing can be started,as against plating, which is a load-bearing implant and weight bearing should be allowed after fractureunion.

- There is an advantage of controlled impaction over nail duringsurgery.

- Using two screw proximal and two to three screws in distalfragments provide better rotational stability.

- Resulting reduced operative time, minimal soft tissue dissection, minimum blood loss and therefore reduced rate of infection.

- Reaming procedure gives advantage of internal bone graftat fracture site at the time of reaming. While incommunitedfracture, a reamer should be just pushed and negotiatedacross communited fragments without any rotatorymovement.

Reamed intramedullary nails are preferred for closedfractures, as reaming allows the use of implants oflarger diameter and offers a high union rate ${ }^{[7]}$. The solidso-called unreamed nails are presently preferred to theexternal fixator as the implant of choice for most open-tibial fractures at the lower third tibia when fracturesdo not extend within $4 \mathrm{~cm}$ of distal tibial end, i.e., fromthe ankle joint ${ }^{[8]}$.

External fixators are associated with complications like need of secondary operation, prolonged healing time and pin tract infection ${ }^{[9,10]}$.

Patients managed with both plate and nail can be mobilized early. Advocates of plating suggest better alignment with this technique. However, plating is associated with wide soft tissue dissection and disruption of the fracture hematoma, which can lead to interference with the normal physiology of bone healing, wound dehiscence, infection, hardware prominence and delayed healing ${ }^{[11-17]}$.

Intramedullary nailing spares the extra-osseous blood supply, allows load-sharing, and avoids extensive soft-tissue dissection ${ }^{[18]}$.

Minimally invasive percutaneous plate osteosynthesis is a newer technique which is associated with minimal soft tissue dissection leading to less disruption of fracture hematoma and preservation of periosteal blood supply with promising results and less wound complications ${ }^{[13,19]}$.

There are many recent changes in the design of intramedullary nail, which are now compliant to this spectrum of fractures. Difficulties in reduction, distal propagation of the fracture, hardware failure, and inadequate distal fixation are some major concerns and have lead to mal-alignment due to which the acceptance of intramedullary nailing as a treatment for distal metaphyseal fractures remains controversial.

However, despite using locking plate, one study revealed that $48 \%$ of the patients required implant removal either for irritation by hardware and skin impingement or infection ${ }^{[20]}$.
The present study was conducted to evaluate the results of distal third tibial shaft fractures treated with Intra-Medullary Interlocking nailing in terms of fracture union rate and complications associated with such a treatment.

\section{Material and Methods}

This is a prospective study between August 2018 toJune 2019; about 52tibial fractures were treated in the Department of Orthopedics and Emergency Health Care at a tertiary care hospital. The inclusion criteria for the present study werethe skeletally mature patients with displaced fractures of tibiain or extending into distal third shaft and metaphysis. Type I and Type II open fractures were included in the study. Thefractures extending into distal tibialarticular surface, open grade III Bfractures were excluded. About 24patients meetingthese criteria were included in the study.

\section{Methods}

The main objective of surgical fracture treatment is to restore sagittal and coronal alignment as well as rotationand length. For distal fractures of the tibia, proper reduction and stable fixation of the distal fragment are of great importance for a good outcome. For the same reason, adequate radiological assessment in and bi-planar anterio-posterior (AP) and lateral intervention are done using an image intensifier intraoperatively.

Anteroposterior and lateral radiographs of the affected leg with knee and extent of comminution. ${ }^{21}$ The fibular fracture was noted, and surgery planned accordingly to fix the fibula. The leg was immobilized in a plaster slab till definitive surgery.

Patients with poor skin condition ${ }^{22}$ were managed with limb elevation, local magnesium sulfate dressing. Patients with compound fractures were taken for immediate debridement under regional anesthesia. It was followed by regular dressing, along with intravenous antibiotics. Routine laboatory investigations included HB, CBC, BSL, LFT.KFT, HIV, HBSAG, ECG, and CXR.

\section{Operative Technique: Intramedullary Nailing}

Surgery was performed under tourniquet and spinal anesthesia under image intensifier television (IITV) control on radiolucent fracture table. Routine antiseptic wash and scrubbing with povidone iodine scrub was done. It was followed by painting with povidone iodine and draping of the operative area. The surgerywas carried out under tourniquet to achieve bloodless operative field and to decrease blood loss.

- Fractures are reduced by closed methods of gentle traction and external manipulation and guide wire passed and fixed in a central position ${ }^{[23]}$ in both AP and lateral view and IITV control and reamed intramedullary nailing done.

- In treating distal third fractures, it is advisable to use temporary polar screw or thick K-wire, so that guide wire, reamer, and subsequent intramedullary nail remain in the center (as there is widening of medullary canal at the diaphysio-metaphyseal junction) so that varus/valgus or anterior posterior angulation can be avoided ${ }^{[24-25]}$.

The patient was positioned supine on anormal regular table with a radiolucent triangular frame kept under the knee joint so that knee is flexed upto 90 degree or breaking the table at the level of knee. Entry point for ante-grade nailing was done by keeping the knee in 90-degree flexion. 
Once the entry point is defined, medullary canal was opened and a ball tipped guide wire passed into the distal fragment across the fracture. Sometimes a reduction tool device had to be used to pass the guide wire and reducing the fracture, which helped the guide wire into the distal fragment correctly in a central placement, thus avoiding varus or valgus malalignment or angulation.

When fixing distal tibial fractures, correct positioning of the guide wire is mandatory, and should be achieved at all times.

Determination of Nail length is important and a crucial step. Intramedullary reaming is done 1 or $1.5 \mathrm{~mm}$ more than the nail chosen for the patient. The guide wire enables correct nail placement.

Guide wire placement in distal fragment should be central in AP and lateral, so that subsequent reaming and nail insertion comes in ideal central position.

Once the fracture is reduced and the nail placedcorrectly, distal locking is performed. Distal tibial fractures usually require bi-planar fixation, so $\mathrm{AP}$.

Interlocking screws may be beneficial. The locking procedure is performed free hand using a drill under image intensifier (Fig-1).

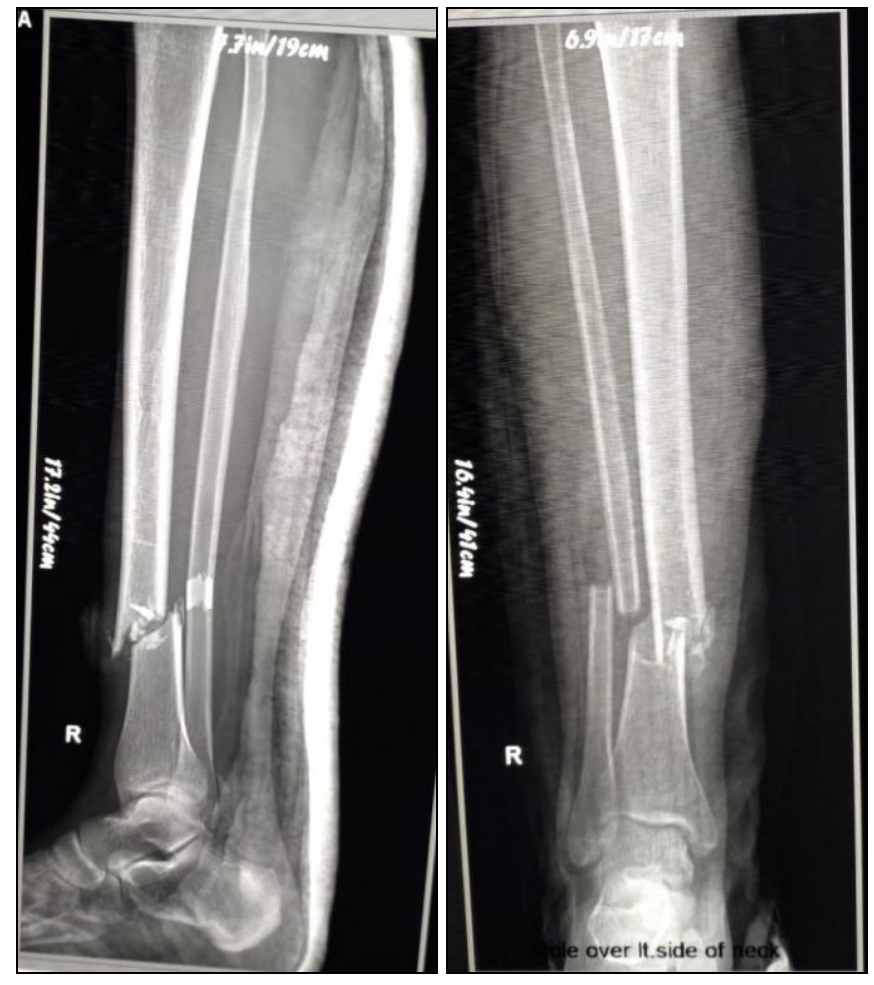

Fig 1: Pre-Operative radiograph of distal $3^{\text {rd }}$ tibia fracture
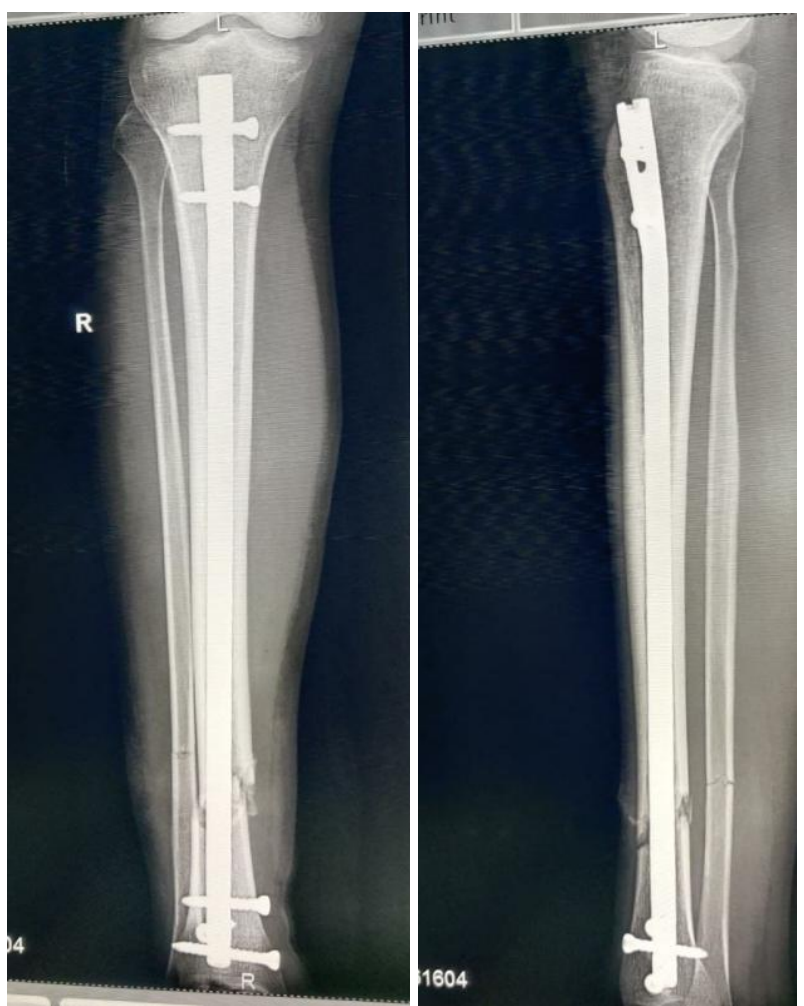

Fig 2: Post-Operative radiograph intramedullary nail and one AP and Two mediolateral screw. 
Once distal locking is done, proximal locking is done using drill assembly device used to insert the nail.

Post operatively, all patients were kept partial weight bearing. They were closely followed up monthly for first 4 months or till union. Subsequently, they were followed after every 3 months till end of 1 year.

\section{Results}

Out of 24 patients included in the study, one patient was lost to follow up after 8 weeks post operatively. Twenty-three out of 24 patients $(85 \%)$, had fracture union without the need for any further surgical intervention (Fig). There were 14 males and 10 females. In majority of cases mode of injury was road traffic accident. All were treated with closed intramedullary interlocking distal tip tibia nail.The average time to union in these 23 patients was 15.6 weeks with range being 14 to 20 weeks. There was no significant difference in the mean time for union based on the type of fracture ( $\left.F^{1 / 4} 0.681 ; p>0.05\right)$.

Mean Procurvatum was 3 degree and mean valgus deviation was $3^{\circ}$ (range of 7 degree valgus to $12^{\circ}$ varus. 2 patients where reduction was lost in first follow up were both elderly males with poor soft tissue condition. Reduction was lost in first follow up, i.e within 4 weeks in both patients. Both patients were counseled for revision surgery but both of them refused to undergo additional surgical procedure.
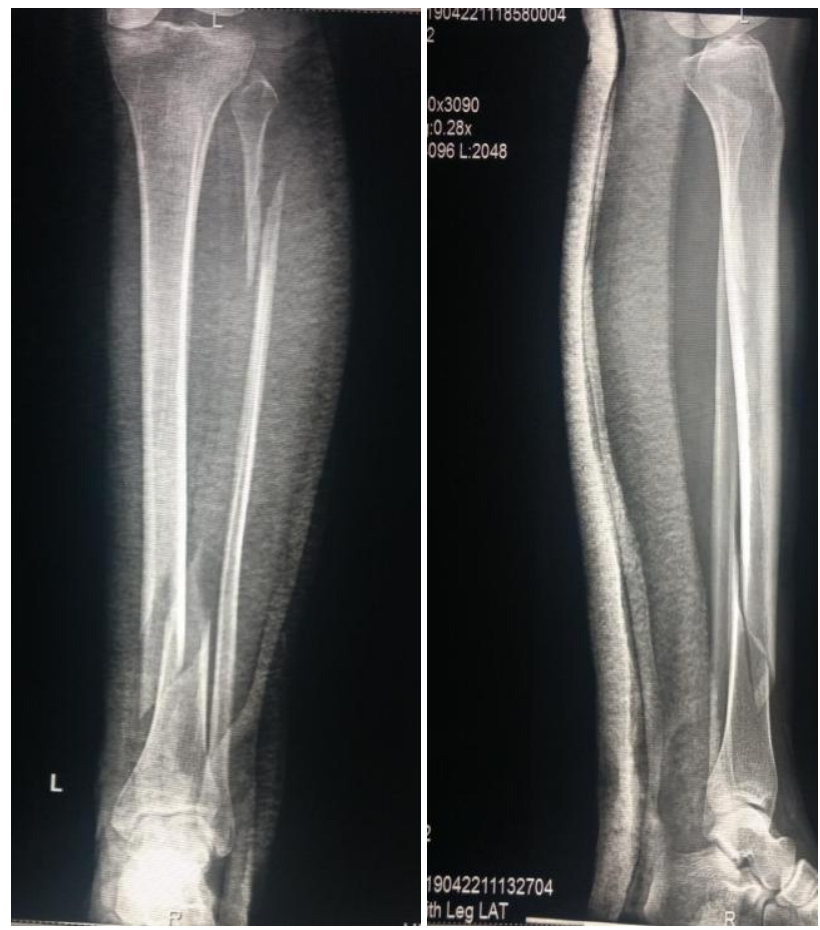

Fig 3: Pre-Operative radiograph of distal $3^{\text {rd }}$ tibia fracture
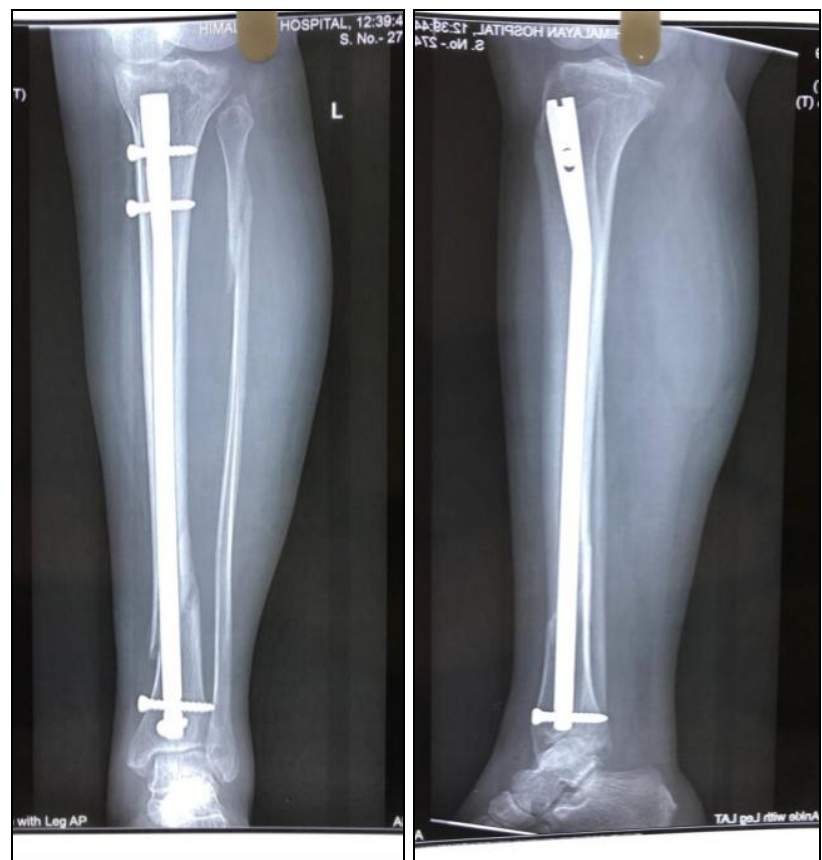

Fig 4: 4 week's old radiograph with distal screw fixation and one AP and one mediolateral screw

One of the patients had varus angle of $12^{\circ}$ post-operatively after ambulation and at the time of union it reduce slightly to $10^{\circ}$, which is still considerable degree of varus. 

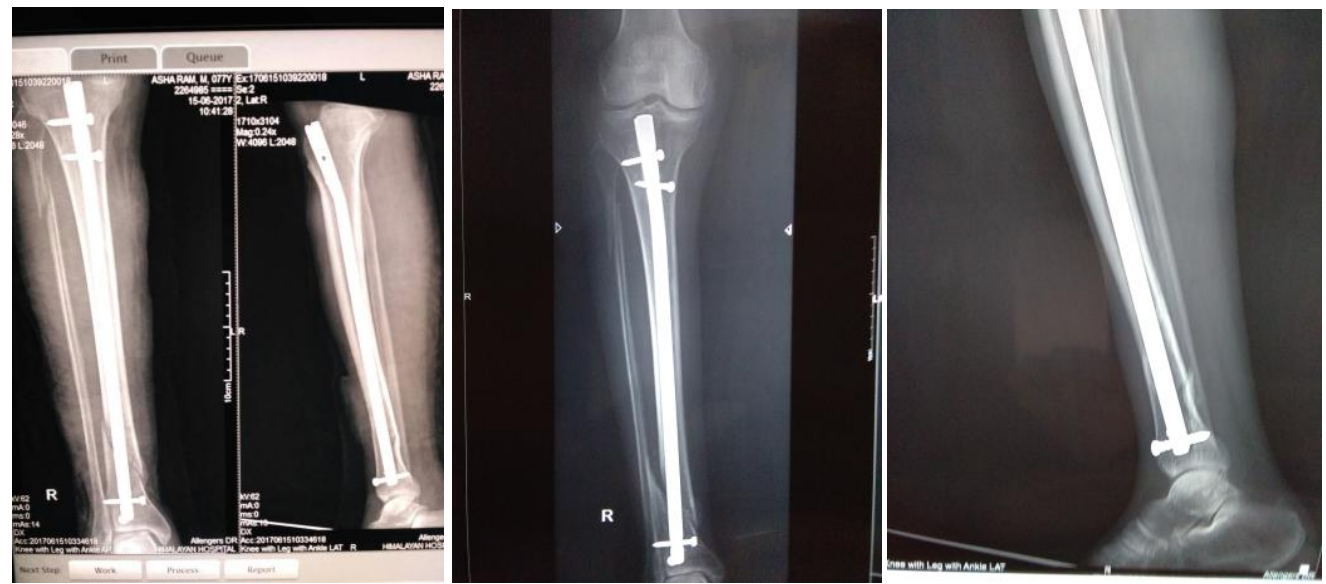

Fig 5: Immediate post op and when patient started walking.
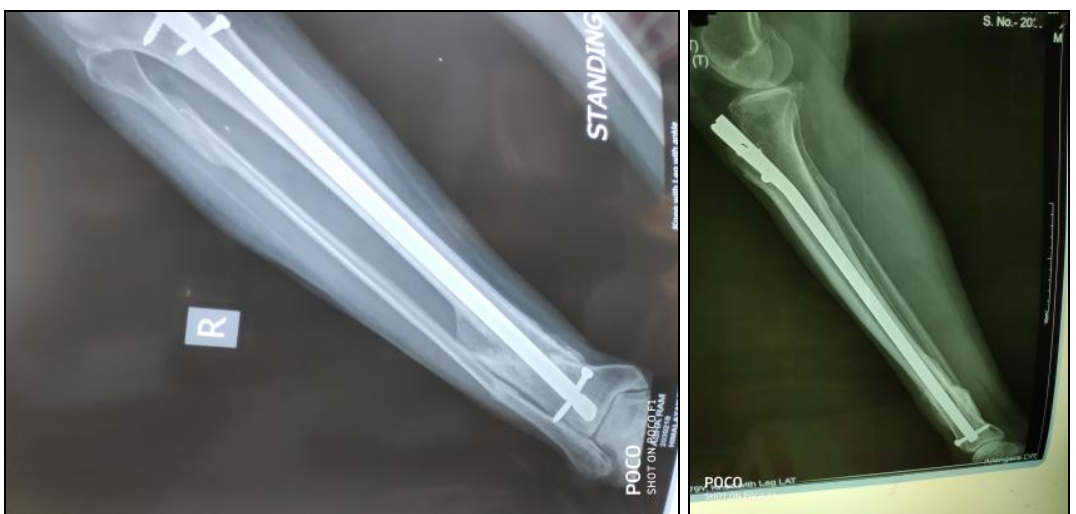

Fig 6: 1 year old post operative radiograph.

Table 1: Demographic data

\begin{tabular}{|c|c|c|c|c|}
\hline S. No & Parameters & Our study & Mugundhan Sengodan ${ }^{[38]}$ & Satish R Gawali et al. $^{\text {[39] }}$ \\
\hline 1 & Total number of Patient & 24 & 20 & 60 \\
\hline 2 & Age & $50 \pm 15$ & 35 & 35 \\
\hline 3 & Male :Female & $14: 10$ & $16: 04$ & $40: 20$ \\
\hline 4 & Varus/valgus angulation & \pm 3 & \pm 1.7 & \pm 1.5 \\
\hline 5 & Union time(weeks) & 15.6 & 11.5 & 18 \\
\hline 6 & Malunion & 02 & - & 02 \\
\hline
\end{tabular}

\section{Discussion}

Intramedullary interlocking nailing has become a wellestablished management option in tibial shaft fracture treatment. However, there still is an ongoing discussion about whether the advantages of intramedullary nailing also apply to distal tibial fracture treatment. In the management of distal tibial fractures, collateral damage including additional trauma or soft tissue laceration should be avoided. In accordance to the delicate soft tissue situation of the distal tibia and the advantages of minimally invasive, symmetric and dynamic fracture fixation options, efforts are increasingly being made to deal with distal tibial fractures - even those with concomitant intraarticular fracture components - with intramedullary nailing devices. Nevertheless, many studies have reported complications such as malalignment and nonunion following intramedullary nailing of distal tibial fractures ${ }^{[27,29,30,31]}$.

The use of sophisticated, less invasive surgical techniques in combination with modern intramedullary nail designs significantly decrease the complication rate, allows distal tibial fractures to be fixed under minimal invasive aspects, and yields advantages of intramedullary fracture fixation.

When considering fractures localized in the distal third of the tibia, the surgeon has multiple options, depending on the fracture location, associated fracture components of the ankle joint, the soft tissue situation, and the patient's general state of health. Conservative management is rather associated with minimally displaced extra articular and intraarticular distal tibial fractures. It is limited to closed fractures only. It requires a long immobilization period and therefore is associated with an increased risk of ankle stiffness ${ }^{[32]}$.

External fixation of distal tibial fractures is an option in open fractures, comminuted fractures or fractures with a difficult soft tissue situation. The control of fragments and reduction is limited. This option is associated with a reduced ankle motion and may be complicated by malalignment, pin infection and nonunion ${ }^{[33]}$.

In fractures of the distal tibia with major involvement of the intraarticular surface of the tibial plafond, fracture reduction and anatomical restoration of the articular surface is mandatory. These cases necessarily require open reduction and internal fixation with plates. These fractures usually need casting or external fixation prior to definitive treatment due to the likely presence of compromised soft tissue and swelling. Open reduction and internal fixation in the area of the distal tibia is always associated with an increased risk of secondary soft tissue breakdown. The vascularity is further disturbed by the additional surgical intervention involved in opening the 
fracture ${ }^{[28]}$.

The advantages of intramedullary fracture fixation are numerous: it is a familiar technique for fixing tibialshaft fractures; it allows osteosynthesis under biological aspects; there is no need to open the fracture site and soft tissue dissection is not necessary; and the blood supply is spared. It enables symmetric, dynamic andload-sharing fracture stabilization without the need to restrict joint ROM. In contrast to open reduction andinternal fixation, intramedullary nailing can be performed initially on the day of admission. The intramedullary approach produces superior results, as described by Robinson ${ }^{[26]}$ and Nork ${ }^{[34]}$, who reporteda $100 \%$ union rate. El Ibrahimi ${ }^{[35]}$ confirmed that good results with no major complications were obtainedwith reamed nailing. Fan [36] reconfirmed that there were no signs of nonunion or malunion. One reported disadvantage/complication of intramedullary nail fixation in distal tibial fractures is implantation failure with nail breakage, which may have been related to the insertion of thin, unreamed nails in the past. Another commonly discussed disadvantage is a potential decrease in fixation stability when nails are used in metaphyseal fractures. This problem can be anticipated by applying a modified surgical technique using blocking screws and modern interlocking nails with threaded locking holes that enhance the angular stability of the construct. Studies that have compared intramedullary nail fixation and plate fixation in distal tibial fractures consider older nail designs that have been improved upon recently, especially in relation to optimizing metaphyseal fracture stability ${ }^{[37]}$. In parallel with this development, new plate designs and techniques for internal fixation have been published that could overcome the reported problems with previous plating techniques and designs, and offer a good alternative to intramedullary fixation.

\section{Conclusion}

We conclude that intramedullary nailing of distal tibial fractures is a reliable method of fracture fixation, possessing the advantages of closed reduction and symmetric fracture stabilization of an area with adelicate soft tissue situation. It is advisable to use temporary polar screw or thick K-wire and Steinmann pin, so that guide wire, reamer, and subsequent intramedullary nail remain in the center. Bi-planer fixation, Anterio-Posterior and medio-lateral interlocking screws, simultaneous fibula fracture fixation at the same level or below are suggested for early mobilization and better outcome.

\section{References}

1. Li B, Yang Y, Jiang LS. Plate fixation versus intramedullary nailing for displaced extra-articular distal tibia fractures: a system review. Eur J Orthop Surg Traumatol 2013;1362-3.

2. Guo J, Tang N, Yang H, Tang T. A prospective, randomised trial comparing closed intramedullary nailing with percutaneous plating in the treatment of distal metaphyseal fractures of the tibia. J Bone Joint Surg Br 2010;92:984-8.

3. Robinson CM, McLauchlan GJ, McLean IP, CourtBrown CM. Distal metaphyseal fractures of the tibia with minimal involvement of the ankle: classification and treatment by locked intramedullary nailing. J Bone Joint Surg Br 1995;77(5):781-787.

4. Gorczyca JT, McKale J, Pugh K, Pienkowski D. Modified tibial nails for treating distal tibia fractures. J
Orthop Trauma 2002;16(1):18-22.

5. Francois J, Vandeputte G, Verheyden F, Nelen G. Percutaneous plate fixation of fractures of the distal tibia. ActaOrthopBelg 2004;70(2):148-154.

6. Tornetta P III, Casey D, Creevy WR. Nailing proximal and distal tibia fractures. Rosemont (IL): Orthopaedic Trauma Association. Final Program \& Membership Directory, 2000, 131-132.

7. Mosheiff R, Safran O, Segal D, Liebergall M. The unreamedtibial nail in the treatment of distal metaphyseal fractures. Injury 1999;30(2):83-90.

8. Richter D, Ostermann PA, Ekkernkamp A, Hahn MP, Muhr G. Distal tibial fracture: an indication for osteosynthesis with an unreamed intramedullary nail? [German] Langenbecks Arch Chir Suppl Kongress 1997;114:1259-1261.

9. Emami A, Mjoberg B, Karlstrom G, Larsson S. Treatment of closed tibial shaft fractures with unilateral external fi xation. Injury 1995;26:299-303.

10. Helland P, Boe A, Molster AO, Solheim E, Hordvik M. Open tibial fractures treated with the Ex-fi -re external fi xation system. ClinOrthopRelat Res 1996;326:209-20.

11. Obremskey WT, Medina M. Comparison of intramedullary nailing of distal third tibial shaft fractures: before and after traumatologists. Orthopedics 2004;27:1180-4.

12. Ibrahimi AE, Shimi M, Daoudi A, Loudyi D, et al. Intramedullary nailing in the management of distal tibial fractures. Currernt Orthopaedic Practice 2009;20(3):300325.

13. Teeny SM, Wiss DA. Open reduction and internal fi xation of tibial plafond fractures. Variables contributing to poor results and complications. ClinOrthop 1993;292:108-17.

14. Im GI, Tae SK. Distal metaphyseal fractures of tibia: a prospective randomized trial of closed reduction and intramedullary nail versus open reduction and plate and screws fixation. J Trauma 2005;59:1219-23.

15. Janssen KW, Biert J, van Kampen A. Treatment of distal tibial fractures: plate versus nail: a retrospective outcome analysis of matched pairs of patients. IntOrthop 2007;31:709-14.

16. Borg T, Larsson S, Lindsjo U. Percutaneous plating of distal tibial fractures. Preliminary results in 21 patients Injury 2004;35:608-14.

17. Frigg R. Locking Compression Plate (LCP). An osteosynthesis plate based on the Dynamic Compression Plate and the Point Contact Fixator (PC-Fix). Injury 2001;32(2):63-6.

18. Nork SE, Schwartz AK, Agel J, et al. Intramedullary nailing of distal metaphysealtibial fractures. J Bone Joint Surg Am 2005;87:1213-1221.

19. Farouk O, Krettek C, Miclau T, Schandelmaier P, Guy P, Tscherne H. Minimally invasive plate osteosynthesis and vascularity: preliminary results of a cadaver injection study. Injury 1997;28(1):A7-A12.

20. Lau TW, Leung F, Chan CF, Chow SP. Wound complication of minimally invasive plate osteosynthesis in distal tibia fractures. IntOrthop 2008;32:697-703.

21. Perren SM. Evolution of the internal fi xation of long bone fractures. The scientifi c basis of biological internal fi xation: choosing a new balance between stability and biology. J Bone Joint Surg (Br) 2002;84:1093-110.

22. Bonar SK, Marsh JL. Unilateral external fi xation for severe pilon fractures. Foot Ankle 1993;14:57-64. 
23. Emami A, Mjoberg B, Karlstrom G, Larsson S. Treatment of closed tibial shaft fractures with unilateral external fi xation. Injury 1995;26:299-303.

24. Helland P, Boe A, Molster AO, Solheim E, Hordvik M. Open tibial fractures treated with the Ex-fi -re external fi xation system. ClinOrthopRelat Res 1996;326:209-20.

25. Robinson CM, McLauchlan GJ, McLean IP, CourtBrown CM. Distal metaphyseal fractures of the tibia with minimal involvement of the ankle. Classification and treatment by locked intramedullary nailing. J Bone Joint Surg B 1995;77:781-7.

26. Tyllianakis $M$, Megas $P$, Giannikas $D$, Lambiris E. Interlocking intramedullary nailing in distal tibial fractures. Orthopedics 2000;23:805-8.

27. Teeny SM, Wiss DA. Open reduction and internal fixation of tibial plafond fractures. Variables contributing to poor results and complications. ClinOrthop 1993;292:108-17.

28. Obremskey WT, Medina M. Comparison of intramedullary nailing of distal third tibial shaft fractures: before and after traumatologists. Orthopedics 2004;27:1180-4.

29. Dogra AS, Ruiz AL, Thompson NS, Nolan PC. Diametaphyseal distal tibia fractures-treatment with a shortened intramedullary nail: a review of 15 cases. Injury 2000;31:799-804.

30. Vallier HA, Le TT, Bedi A. Radiographic and clinical comparisons of the distal tibia shaft fractures $(4$ to $11 \mathrm{~cm}$ proximal to the plafond): Plating versus intramedullary nailing. J Orthop Trauma 2008;22:307-11.

31. Digby JM, Holloway GM, Webb JK. A study of function after tibial cast bracing. Injury 1983;14:432-9.

32. Anglen JO. Early outcome of hybrid external fixation for fracture of the distal tibia. J Orthop Trauma 1999;13:927.

33. Nork SE, Schwartz AK, Agel J, Holt SK, Schrick JL, Winquist RA. Intramedullary nailing of distal metaphysealtibial fractures. J Bone Joint Surg A 2005;87:1213-21.

34. El-Ibrahimi A, Shime M, Daoudi A. Intramedullary nailing in the management of distal tibial fractures. CurrOrthop Practice 2009;20:300-3.

35. Fan CY, Chiang CC, Chuang TY, Chiu FY, Chen TH. Interlocking nails for displaced metaphyseal fractures of the distal tibia. Injury 2005;36:669-74.

36. Zelle BA, Bhandari M, Espiritu M, Koval KJ, Zlowodzki M. Treatment of distal fractures without articular involvement: a systematic review of 1125 fractures. J Orthop Trauma 2006;20:76-9.

37. Moongilpatti Sengodan M, Vaidyanathan S, Karunananda-ganapathy S, Subbiah Subramanian S, Rajamani SG. Distal tibialmetaphyseal fractures: does blocking screw extend the indication of intramedullary nailing? ISRN Orthop, 2014, 542-623.

38. Satish Gawali $\mathrm{R}$ et al. Management of fracture of distal third tibia by interlocking nailing. JFAS (AP) 2016;3(1):15-22. 